\title{
Nano Curcumin Effect For Kidney Fibrotic Caused By Unilateral Ureter Obstruction Based On Expression Matrix Metalloproteinase-9
}

\author{
Alvarino $^{1}$, Yanwirasti ${ }^{2}$ \\ \{alvarinouro@yahoo.com ${ }^{1}$, yanwirasti@yahoo.com $\left.{ }^{2}\right\}$ \\ Department of Surgery, Division of Urology, M. Djamil Hospital/Faculty of Medicine, Universitas \\ Andalas, Padang, Indonesia ${ }^{1}$ \\ Department of Anatomy, Faculty of Medicine, Universitas Andalas, Padang, Indonesia ${ }^{2}$
}

\begin{abstract}
Upper urinary tract obstruction is a such a problem in urology which can occur in any phase of human life and can occur along the upper urinary tract. This condition can lead to hydronephrosis. It can make glomerular endothelial dysfunction and change kidney structure such as interstitial fibrotic, tubular atrophy and apoptosis and also intestinal inflammation. Curcumin is one of the bioactive compounds from temulawak (Curcuma xanthorhiza Roxb) and turmeric (Curcuma longa) which is expected to resolve fibrotic, this is because the nature of the anti-oxidative and anti-inflammatory suppressing the expression of MMP-9. This was an experimental study with post test control group design in 34 adult male wistar rats aged 10-12 weeks were tied unilateral ureter. There are two treatment groups. The statistical tests using t-test shows significant differences $(p<0.05)$ in that a variable. The group of rats without administration of nano curcumin also has more fibrosis area with score $4(>81 \%)$ about $64,7 \%$, whereas the group of rats which given nanocurcumin has fibrosis area score $3(51 \%-80 \%)$ about $52,9 \%$. The statistical tests using Mann-Whitney show a significant difference $(\mathrm{p}<0.05)$. TGF- $\beta 1$ is the main stimulator of fibroblast activation. It could stimulate fibroblast proliferation too, and we found that curcumin could inhibit in vitro proliferation respond related with dose and interval of administration. Curcumin supplementation was significantly reduced fibrosis. In order hand, different curcumin concentration was inhibited by NRK-49F and stimulated by TGF$\beta 1$. Nano curcumin can suppress the expression of MMP-9 and the extent of renal fibrosis in rats with unilateral ureteral obstruction.
\end{abstract}

Keywords: Kidney Fibrosis, MMP-9, Nano Curcumin.

\section{Introduction}

Upper urinary tract obstruction can occur at every phase of human life, and the location at which it occurs can be along the upper urinary tract. This condition could cause hydronephrosis, that is the occurrence of pelvic or kidney calyx dilatation. As a result of hydronephrosis, there is dysfunction on glomerular endothelial and change of kidney structure, such as interstitial fibrosis, tubular atrophy, apoptosis, and interstitial inflammation.[1]

There are many factors predicted having a role in the occurrence of the process above, including oxidative stress and inflammation. Increasing of hydrostatic pressure in kidney tubular will lead to the occurrence of apoptosis, necrosis, and tubular trauma which will cause fibrosis. 
Moreover, it can also lead to loss of kidney nephron main function, activation of interstitial myofibroblast, and extracellular matrix deposit.[2],[3].

Mechanism of kidney failure on urinary tract obstruction is the occurrence of fibrosis in the kidney which has that obstruction [4]. This obstruction condition could increase tissue inhibitor of metalloproteinases(TIMPs) synthesis which can decrease the activity of MMPs and will increase extracellular matrix cumulation. All this time, MMPs was considered as an antifibrinolytic because of its ability to degrade and remodel extracellular matrix. MMP-9 which is also known as gelatinase B is a part of MMPs, which is found in kidney tubular. MMP-9 is kidney fibrosis because it will break osteopontin, induce epithelial-mesenchymal transition (EMT), activate fibroblast, pericyte-myofibroblast transdifferentiation, and endothelialmesenchymal transition (EndoMT). MMP-9 is the product of kidney tubular TGF- $\beta 1$ regulation and macrophage secretion. It will cause increasing of extracellular matrix and myofibroblast accumulation.[1], [5], [6].

Currently, the treatment given to this condition are from angiotensin-converting enzyme inhibitor (ACE-i) and angiotensin II receptor blocker (ARB) group, which both of them are usually used in hypertension treatment. A study conducted by $\mathrm{Wu}$ et al. concluded that angiotensin II receptor blocker (ARB and aliskiren could increase kidney protection from fibrosis and inflammation for 14 days of obstruction in Wistar mice ureter.[7],[8].

Nevertheless, because drugs chemical side effect is still high so that people start turning to phytopharmacy. Natural substances which are well known to be used for medical treatment is temulawak (CurcumaxanthorrhizaRoxb.) and turmeric (Curcuma longa). Temulawak and turmeric are known to have an antioxidative, anti-inflammatory, and antimicrobial effect because they contain curcumin compound. Curcuminoid in temulawak and turmeric is composed of 2 compounds, those are curcumin and desmethoxycurcumin, while in turmeric, it is added by one more compound, that is bisdesmestoxicurcumin. This was reported for the first time by Lampe and Milobedeska in 1913.[9].

Curcumin can inhibit TGF- $\beta 1$ by influencing kidney epithelial tubular cell epithelial to mesenchymal transition (EMT) through ERK-dependent and PPAR- $\gamma$ dependent pathway, so that fibrosis will be decreased.[10], [11].

Curcumin bioavailability is poor because of lack of absorption (5\%), fastly metabolised, and fastly eliminated. In order to increase the absorption of curcumin, so it is made in nano size. Nanocurcumin was firstly reported by Bisht et al., by making curcumin in nano size. This nano size curcumin is not similar to general curcumin, because it is soluble in water. In an in-vitro study, the amount of curcumin found with nano size curcumin is similar with general curcumin, but in in-vivo study, the amount of nanocurcumin in mice brain was found increased by $96 \%$ compared with general curcumin. This study will investigate the benefit of nanocurcumin in compressing MMP-9 expression and fibrosis in kidney led by unilateral ureter obstruction.[12], [13].

\section{Materials and Methods}

This is an experimental study with post-test control group design. The population is male, healthy Wistar mice with age around 3 months and weight between 200-250 gram. They were divided into 2 groups which each of them contains 17 mice so that the total of mice is 34 . The mice were adapted for 1 week. They were anaesthetized with diethyl ether before undergoing surgery by slashing the stomach at the midline. Then, the right ureter was identified and tied 
using silk 4-0 at the proximal site. After that, make sure the tie was good, there was no urine leakage after cutting the distal part of the tie. The distal part of the ureter that had been cut was also tied. The stomach was then closed using silk 3.0 sutures.

After that, all mice were given general food and drank per oral after regaining consciousness. However, in one group, the intake was added with curcumin in nano size which is turmeric (Curcuma longa) bioactive compound, produced by Miso N South Korea with 100 $\mathrm{mg} / \mathrm{kg}$ dose once a day soluted in water. It was given via sonde while the other food was not. After 28 days, we underwent laparotomy again and took the right mice kidney that had been tied.[14].

Subsequently, we took the cortex part of the kidney and examined MMP-9 expression in mice kidney with immunohistochemistry method. We counted MMP-9 producer cell coloured old brown in 100 cells in immunohistochemistry method (400X). For kidney fibrosis in histochemistry, we used Masson Trichrome. Kidney interstitial tubular fibrosis distribution value is quantitative value in percentage $(\%)$ of blue intensity distribution or the amount of atrophy in 100 tubular per visual field of the microscope with 40 times of magnification. The result was the scored [15], [16].

\section{Result}

Table 1. The effect of nanocurcumin to mean percentage of MMP-9 expression in the kidney with bilateral ureter obstruction.

\begin{tabular}{lllll}
\hline \multirow{2}{*}{ Nano Curcumin Administration } & Mean & $\begin{array}{l}\text { Standard } \\
\text { Deviation }\end{array}$ & of & $\mathrm{P}$ \\
\hline \multirow{2}{*}{ MMP-9 } & With nano curcumin & 21,47 & 6,45 & \multirow{2}{*}{0,001} \\
& Without nano curcumin & 12,18 & 5,41 & \\
\hline
\end{tabular}

That table showed that the result of t-test analysis to MMP-9 expression with or without nano curcumin had significant differences $(\mathrm{p}<0,05)$.

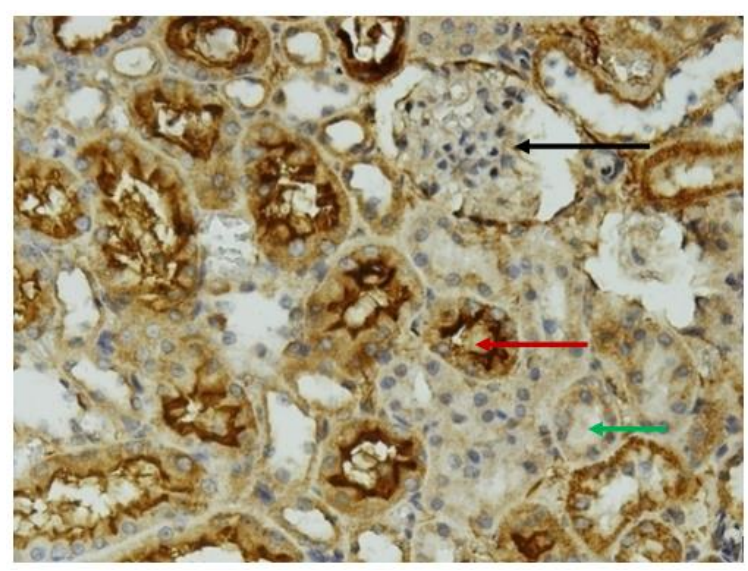

Fig. 1. MMP-9 expression in normal kidney cortex (IHK 400X). The cells producing MMP-9 did not

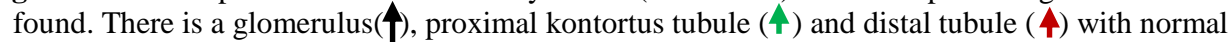
morphology, size, and epitel. 


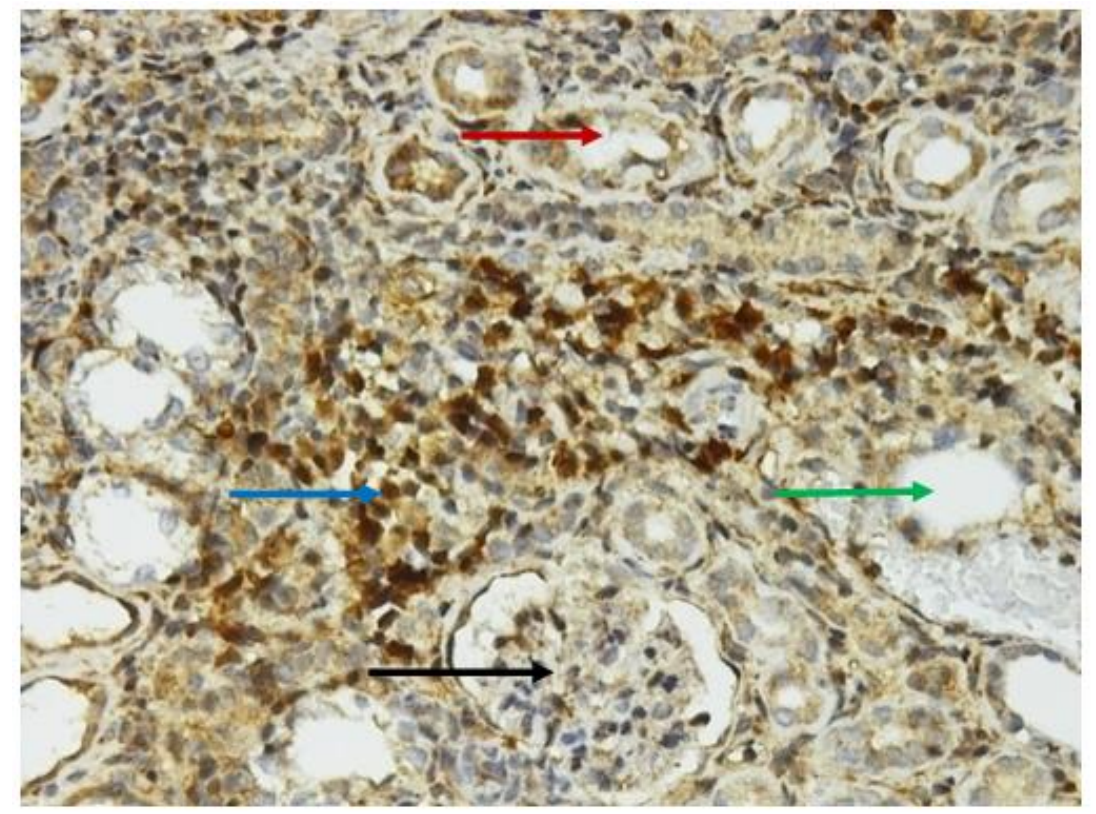

Fig. 2. The MMP-9 expression in kidney cortex with ureteral obstruction (IHK 400X). There is a cell producingTGF- $\beta 1$ with brown colours $(\boldsymbol{\uparrow})$ There is also glomerulus $(\boldsymbol{\uparrow})$, proximal tubule $(\boldsymbol{\uparrow})$ and distal tubule $(\uparrow)$ with irregular shape and destroyed epitel.

Table 2. The effect of nano curcumin administration to the percentage of fibrosis area in the kidney with unilateral ureter obstruction.

\begin{tabular}{|c|c|c|c|c|c|c|c|}
\hline \multirow[b]{2}{*}{ Group } & & \multicolumn{4}{|c|}{ Fibrosis Area ( Score ) } & \multirow[b]{2}{*}{ Total } & \multirow[b]{2}{*}{$P$} \\
\hline & & $\begin{array}{l}<20 \% \\
\text { (1) }\end{array}$ & $\begin{array}{l}20 \%-50 \% \\
\text { (2) }\end{array}$ & $\begin{array}{l}51 \%-80 \% \\
\text { (3) }\end{array}$ & $\begin{array}{l}>80 \% \\
(4)\end{array}$ & & \\
\hline Without nano & $\mathrm{F}$ & 0 & 1 & 5 & 11 & 17 & \multirow{4}{*}{0,004} \\
\hline curcumin & $\%$ & 0 & 5,9 & 29,4 & 64,7 & 100 & \\
\hline With & $\mathrm{F}$ & 2 & 3 & 9 & 3 & 17 & \\
\hline nanocurcumin & $\%$ & 11,9 & 17,6 & 52,9 & 17,6 & 100 & \\
\hline
\end{tabular}

That table showed that there is a significant difference in fibrosis area of rats with or without nano curcumin administration as per the result of the Mann-Whitney test $(p<0,05)$ 


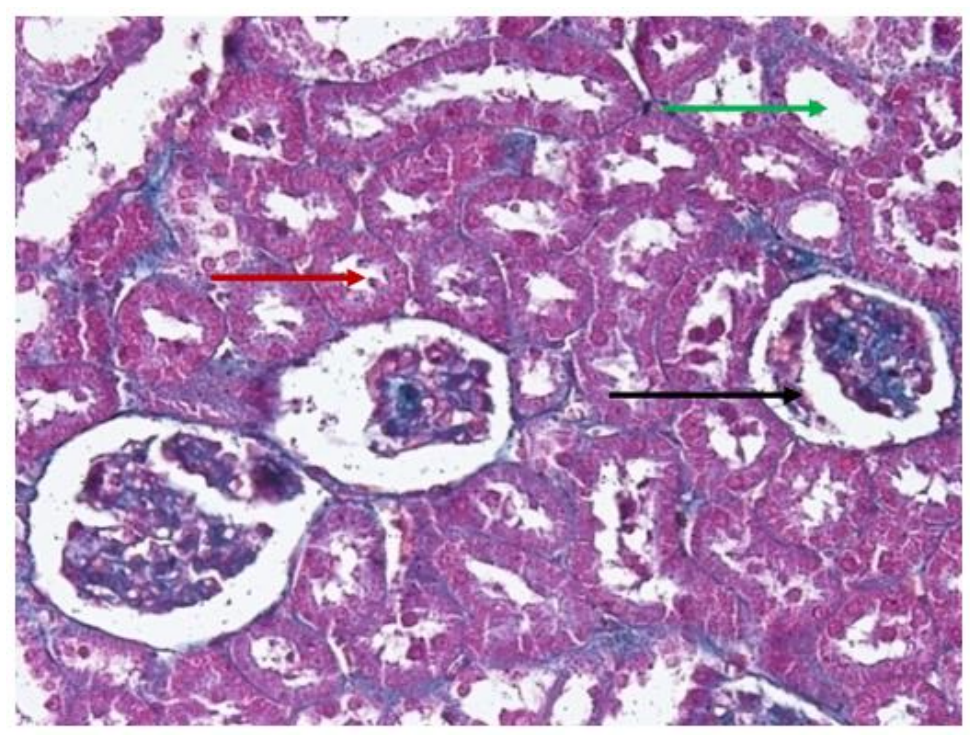

Fig. 2.1 Histochemistry analysis in normal kidney cortex (MT 400X). There is no fibrosis intertubular

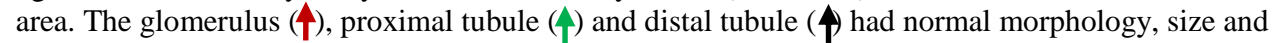
epitel. There is no atrophy tubular.

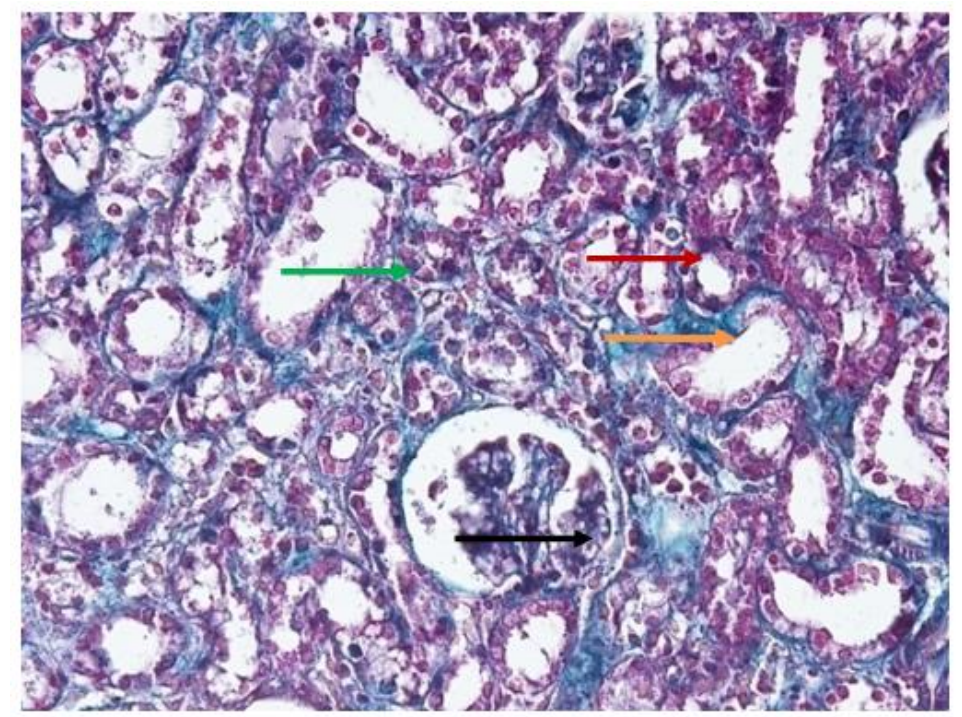

Fig. 3. Histochemistry analysis in the cortex of kidney with ureteral obstruction (MT 400X)There is wide fibrosis in interstitial tissue with the blue colour $(\mathbf{\uparrow})$. There is a glomerulus $(\uparrow)$ with destroyed epitel. There is alsoatrophy and irregular morphology in proximal tubule( $\mathbf{\uparrow})$ and distal tubule ( $\mathbf{\uparrow})$ because of the suppression from fibrosis tissue in interstitial. 


\section{Discussion}

\subsection{The Effect of Nanocurcumin Intake on MMP-9 Expression in Suppressing Kidney Fibrosis Caused by Unilateral Ureter Obstruction}

In recent years, the evidence collected have concluded that curcumin affects inhibiting MMPs significantly in malignancy, arthritis, and ulcer [17]. The molecular mechanism found in this study was similar in a blood vessel. Curcumin inhibits EMPRIN, MMP-9, and MMP-13 via PKC pathway and dependent on AMPK-MAPK in phorbol 12-myristate 13-acetate (PMA) by induced macrophage cell. Increasing of expression and activation of MMP-13, MMP-9, and EMMPRIN correlate with advanced lesion followed by broken plaque and myocardial infarct that can be inhibited by curcumin.[18], [19].

EMMPRIN was reported to be able to stimulate MMP-9 secretion in monocytes and had a positive correlation with MMP-13 or several MMPs in other cells also activateMMP-9 caused by plaque. Excessive expression of MMP-9 and EMMPRIN in monocytes will cause plaque development and destabilisation. The break of the plaque will be considered as the result of extracellular matrix component degradation which forms a macrophage-derived matrix, metalloproteinase matrix (MMPs). Curcumin inhibits monocytes adhesion to endothelial cells and decreases human aortic smooth muscle cells (HASMCs) migration by suppressing MMP9 expression through NF- $\kappa B$ down-regulation.[20], [21],[22], [23], [24], [25], [26].

A study by Gupta et al., in prostatic cancer, MMP-9 activation knockdown was correlated with angiogenesis via regulation of VEGF (vascular endothelial growth factor) and Cancer cell angiostatin secretion. [27].

The previous study has shown that macrophage has important role in the development of kidney fibrosis in every form of chronic kidney disease.[28].

\subsection{The Effect of Nano Curcumin to The Area of Tubulointerstitial Fibrosis and Renal Tubular Atrophy due to Unilateral Ureteral Obstruction}

Renal fibrosis which characterized by the accumulation of fibroblasts and matrix proteins with function loss of neurons is the primary pathology of progressive kidney damage. Tubulointerstitial fibrosis is considered the final process of renal fibrosis. The pathogenesis of tubulointerstitial fibrosis is a transition of mesenchymal-epithelial (EMT) which is a process of the epithelial cells transition into mesenkim in phenotypes. TGF- $\beta$ is known as the EMT main inducer. TGF- $\beta$ induces EMT via the pathways of Smad-independent and dependent. [29], [30]

The increase in $\alpha$-SMA expression and plasminogen activator inhibitor-1 (PAI-1) and a decrease in the expression of E-cadherin is the cause of the IMT on renal tubular epithelial cells, E-cadherin suppression considered as the initial process the change of TGF- $\beta 1$ to EMT. $\alpha$-SMA is an important fibroblasts marker, have a role in the formation of transfer cells and their capacity for migration and invasive. PAI-1 is the potent inhibitor of uPA/tPA (tissue plasminogen activator/urokinase) which played a major role in the accumulation and degradation of the extracellular matrix (ECM) and was the main picture of the fibrosis process. With the administration of curcumin, there is a reduction in the levels of $\alpha$-SMA and PAI-1 induced by TGF- $\beta 1$, and the E-cadherin loss is inhibited. [10], [31], [32], [33].

Curcumin is also reported to activate PPAR- $\gamma$, but the exact mechanism is not yet known

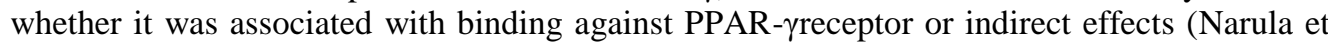
al.,2009). Li et al. (2013) in his study suggest that the curcumin can supress TGF- $\beta 1$ then lowers 
the EMT on the renal tubule cell via the ERK-dependent and PPAR- $\gamma$ dependent pathways. [10], [34].

It was reported that PPAR- $\gamma$ receptor activation could induce the anti-proliferative and antifibrotic effects by the modulation path of TGF- $\beta 1$. PPAR- $\gamma$ (Peroxisome ProliferatorActivated Receptor- $\gamma$ ) is a transcription factor nuclear receptor. The bonds of PPAR- $\gamma$ consists of natural and synthetic. Agonis PPAR- $\gamma$ has a protective effect on kidney disease. [21], [35]

Curcumin triggered the expression of PPAR- $\gamma$ then it will inhibit the phosphorylation of PPAR- $\gamma$ and helped nuclear translocation of PPAR- $\gamma$ to epithelial cell of renal tubular. Curcumin can activate PPAR- $\gamma$ but whether there is a bond or not still debated. The mechanism of curcumin that triggered the expression of PPAR $-\gamma$ is not yet understood. Activation of PPAR- $\gamma$ by curcumin is essential to inhibit the occurrence of EMT.[36].

Renal fibrosis is primarily characterized by the activation and proliferation of interstitial fibroblasts, common pathological changes in patients with PGK and is characterized by tubular atrophy and excessive deposition of extracellular matrix(ECM) including fibronectin and collagen. On damaged kidney, fibroblasts transformed into myofibroblast cells with phenotype activation characterized by expression of $\alpha$-smooth muscle actin ( $\alpha$-SMA) and increased proliferation and production of ECM. [28], [29], [37].

Curcumin is polyphenol compound which isolated from turmeric (Curcuma longa). Preceding studies present that curcumin inducted PPAR $-\gamma$ gene expression dramatically that activated by hepatic stellate cells (HSC) and heart fibroblast in rat and facilitated transactivation activity, which heading to HSC inhibition and fibroblast proliferation and ECM production suppression.[38] . The previous study reported that curcumin had an antifibrotic effect such as:

a. Reduce EMT [39]

b. Stimulate apoptosis in myofibroblast [37]

c. Modulate respond inflammation [40]

d. Block NF-kB signalling, ERK signalling, and Rac1 / MLK3 / JNK pathway [41]

e. Oxidative weakening stress [42].

\section{Conclusions}

1. Nano curcumin supplementation could suppress MMP-9 expression in rat's kidney that suffers unilateral ureter obstruction.

2. Nano curcumin supplementation could reduce fibrosis area in interstitial and tubular atrophy of rat's kidney that suffers unilateral ureter obstruction.

\section{References}

[1] Singh I, Strandhoy JW, Assimos DG. Pathophysiology of Urinary Tract Obstruction. In Kavossi LR, Novick AC, Partin AW, Peters CA Cambell-Walls Urology $10^{\text {th }}$ ed. Phyladelpia Sanders Elsevier 2012:1088-1121.

[2] Pat B, Tang T, Kong C, Diannewatters, Johnson D. Activation of ERK in Renal Fibrosis After Unilateral Ureteral Obstruction. Modulation by Antioxidants. Kidney International 2005: 67:931-943.

[3] Picard N, Baum O, Vogetseder A, Kaissling B, Le Hir M. Origin of Renal Myofibroblast in The Model of Unilateral Ureter Obstruction in The Rat. Histochem Cell Biol 130(1) 2008: 141-155. 
[4] Peters CA, Chevalier RL. Congenital Urinary Obstruction : Pathophysiology And Clinical Evaluation. Campbell-Walls Urology $10^{\text {th }}$ Phyladelphia Sanders Elsevier 2012 :3028-3037.

[5] Tan TK, ZhengG, Hsu TT, Lee SR, Zhang J. Matrix Metalloproteinase-9 Of Tubular and Macrophage Origin Contributes To The Pathogenesis Of Renal Fibrosis Via Macrophage Recruitment Through Osteopontin Cleavage. Lab Invest 2013:93(4):434 - 449.

[6] Zhao H, Dong Y, Tian X, Tan TK, Liu Z.Matrix Metalloproteinases Contribute to Kidney Fibrosis in Chronic Kidney Diseases. World J Nephrol 2013: 2(3):84-89.

[7] Klahr S, Morrissey J. Obstructive Nephropathy and Renal Fibrosis : The Role of Bone Morphogenic Protein-7 and Hepatocyte Growth Factor. Kidney International Vol. 64: Supplement 2003:87: 105-112.

[8] Wu W, Chang C, Chiu Y, Ku C, Wen M.A Reduction of Unilateral Ureteral ObstructionInduced Renal Fibrosis by A Therapy Combining Valsartan with Aliskiren. American Journal of Physyology Renal Physiolog 2010: 299: 929-941.

[9] Sidik, Mulyono MW, Mutadi A. Temulawak (Curcuma xanthorriza roxb.). Phytomedica. Jakarta. 1995.

[10] Li R, Wang Y, Liu Y, Chen Q, Fu W. CurcuminInhibit Transforming Growth Factor B1 Induced Emt Via PPAR- $\gamma$ Pathway Tubular Epithelial Cell. PLosOne 8(3) 2013:e58848.

[11] Cao J, Han Z, Tian L, Chen K, Fan Y, 2014. Curcumin Inhibits EMMPRIN and MMP-9 Expression Through AMPK-MAPK and PKC Signaling in PMA Induced Macrophague. J Tansl Med 2014: 12 (266):1-10.

[12] Bisht S, Khan MA,Bekhit M, Bai H, Cornish T. A Polymeric Nanoparticle Formulation of Curcumin (Nanocurcumin) Ameliorates $\mathrm{CCi}_{4}$ Induced Hepatic Injury and Fibrosis Through Reduction of Pro Inflammatory Cytokines And Stellate Cell Activation. Lab Invest 2011:91(9):1383-95.

[13] [13] Tsai YM, Chien CF, Lin LC, Tsai TH.Curcumin and ItsNanoFormulation : The Kinetics of Tissue Distribution and Blood Brain Barrier Penetration.Int J Pharm. 2011 : 416(1):331-8.

[14] Hashem RM, Soliman HM, Shaapan SF, 2008. Turmeric-Based Diet Can Delay Apoptosis without Modulating NFKB in Unilateral Ureteral Obstruction in Rats. J Pharm Pharmacol. $2008: 60: 83-89$.

[15] Shi Z, Stack MS. An Update on Immunohistochemistry in Translational Cancer Research CancerTransl Med $2015: 1: 115-122$.

[16] Farris AB, Chan S, Climenhaga B, Adam B, Bellamy COC, et al., 2014. Banff Fibrosis Study : Multicenter Visual Assesment and Computerized Analysis Of Interstitial Fibrosis in Kidney Biopsies. Am J Transplant. 2014:897-907.

[17] Kumar D, Kumar M, Saravanan C, Singh SK. Curcumin: A Potential Candidate for Matrix Metalloproteinase Inhibitors. Expert OpinTher Targets: 2012: 959-972.

[18] Cao F, Liu T, Xu Y, Xu D, FengS.Curcumin Inhibits Cell Proliferation and Promotes Apoptosis in Human Osteoclastoma Cell through MMP-9, NF-אB and JNK Signaling Pathways,Int J ClinExpPathol 2015:6037-6045

[19] Cimmino G, Ragni M, Cirillo P, Petrillo G, Loffredo F, Chiariello M, et al. C-Reactive Protein Induces Expression of Matrix Metalloproteinase-9: a Possible Link Between Inflammation and Plaque Rupture. Int J Cardiol2013: 168:981-986.

[20] Kim JY, Kim WJ, Kim H, Suk K, Lee WH. The Stimulation of CD147 Induces MMP-9 Expression through ERK and NF-kappaB in Macrophages: Implication for Atherosclerosis. IImmuneNetw: 2009:90-97.

[21] Yang D, Wang J, Ni J, Shang S, Liu L, Xiang J, et al. Temporal Expression of Metalloproteinase-8 and -13 and Their Relationships with Extracellular Matrix Metalloproteinase Inducer in The Development of Ligature Induced Periodontitis in Rats. J Periodontal Res. 2013:48: 411-419.

[22] Schmidt R, Bultmann A, Ungerer M, Joghetaei N, Bulbul O, Thieme S, et al. Extracellular Matrix Metalloproteinase Inducer Regulates Matrix Metalloproteinase Activity in Cardiovascular Cells: Implications in Acute Myocardial Infarction. Circulation 2006: 113:834-841. 
[23] Yoon YW, Kwon HM, Hwang KC, Choi EY, Hong BK, Kim D, et al. Upstream Regulation of Matrix Metalloproteinase by EMMPRIN : Extracellular Matrix Metalloproteinase Inducer in Advanced Atherosclerotic Plaque. Atherosclerosis 2005: 180:37-44.

[24] Watanabe N, Ikeda U. Matrix Metalloproteinases and Atherosclerosis. CurrAtheroscler Rep, 2004:6:112-120.

[25] Coban D, Milenkovic D, Chanet A, Khallou-Laschet J, Sabbe L, Palagani A, et al. Dietary Curcumin Inhibits Atherosclerosis by Affecting the Expression of Genes Involved in Leukocyte Adhesion and Transendothelial Migration. MolNutr Food Res : 56, 2012 :12701281.

[26] Yu YM, Lin HC. Curcumin Prevents Human Aortic Smooth Muscle Cells Migration by Inhibiting Of Mmp-9 Expression. Nutr Metab Cardiovasc Dis: 20, 2010 : 125-132.

[27] Gupta A, Zhou CQ, Chellaiah MA. Osteopontin and MMP-9: Associations with VEGF Expression/Secretion and Angiogenesis in PC3 Prostate Cancer Cells Cancers:5, 2013: 617638.

[28] Duffield JS, 2010. Macrophages and Immunologic Inflammation Of The Kidney. SeminNephrol: 30, 2010: 234-254

[29] Zeisberg M, Kalluri R. The Role of Epithelial-to-Mesenchymal Transition in Renal Fibrosis. J Mol Med. 2004: 82: 175-181.

[30] Derynck R, Zhang YE. Smad-Dependent and Smad-Independent Pathways in TGF-b Family Signalling. Nature 425, 2003: 577-584.

[31] Willis BC, Borok Z. TGF- $\beta$-induced EMT : Mechanisms and Implications for Fibrotic Lung Disease. Am J Physiol Lung Cell, 2007: 293: L525-L534.

[32] Ghosh AK, Vaughan DE. PAI-1 in Tissue Fibrosis. J Physiol 227, 2012: 493-507.

[33] Hu Y, Liang H, Du Y, Zhu Y, Wang X. Curcumin Inhibits Transforming Growth Factor- $\beta$ Activity via Inhibition of Smad Signaling in HK-2 Cells. Am J Nephrol 31, 2010: 332-341.

[34] Narala VR, Smith MR, Adapala RK, Ranga R, Panati K. Curcumin is Not A Ligand for Peroxisome Proliferator-Activated Receptor-Gamma. Gene Ther Mol Biol 13, 2009: 20-25.

[35] Kawai T, Masaki T, Doi S, Arakawa T, Yokoyama Y, 2008. PPAR- $\gamma$ Agonist Attenuates Renal Interstitial Fibrosis and Inflammation Through Reduction of TGF-b. Laboratory Investigation 89, 2008: 47-58.

[36] Zhou X, Zhang J, Xu C, Wag W. Curcumin Ameliorates Renal Fibrosis by Inhibiting Local Fibroblast Proliferation and Extracellular Matrix Deposition.J Pharmacol Sci:126, 2016:344350.

[37] Zhang X, Chen Q, Wang Y, Peng W, Cai H. Effects of Curcumin on Ion Channels and Transporters. Front Physiol $2014: 11: 94$.

[38] Meng Z, Yu XH. Curcumin Attenuates Cardiac Fibrosis in Spontaneously Hypertensive Rats through PPAR-g Activation. ActaPharmacol Sin. :35, 2014:1247-1256.

[39] Li Y, Chen ZQ, Li YD. Effects of Curcumin on The Epithelial Mesenchymal Transition and TGF-beta/Smads Signaling Pathway in Unilateral Ureteral Obstruction Rats. Zhongguo Zhong Xi Yi Jie He ZaZhi.: 31, 2011:1224-1228.

[40] Cho YJ, Yi CO, Jeon BT, Jeong YY, Kang GM, Lee JE, et al. Curcumin Attenuates RadiationInduced Inflammation and Fibrosis in Rat Lungs. Korean J Physiol Pharmacol :17, 2013:267274.

[41] Lin CH, Yu MC, Tung WH, Chen TT, Yu CC, Weng CM, et al. Connective Tissue Growth Factor Induces Collagen I Expression in Human Lung Fibroblasts Through The Rac1/MLK3/JNK/AP-1 Pathway. BiochimBiophys Acta.;33, 2013:2823-2833.

[42] Soetikno V, Sari FR, Lakshmanan AP, Arumugam S, Harima M, Suzuki K, et al. Curcumin Alleviates Oxidative Stress, Inflammation, and Renal Fibrosis in Remnant Kidney Through The Nrf2-Keap1 Pathway. Mol Nutr Food Res. :57, 2013:1649-1659. 